\title{
A Comparative study of Mental Health among Employed and Unemployed Young Technical Personnel
}

\author{
Dr. Manju Khokhar*, Dr. Vibha Nagar**
}

\section{ABSTRACT:}

The Purpose of the present research paper is to highlight the mental health status of employed and unemployed young technical personnel who were recently employed and also on those who remain unemployed. Mental health status was measured by M.M.H.S.I. developed by Kumar and Thakur (1986). t-test was used to find out significant difference. Results obtained by t-test showed that young technical personnel who were employed have better mental health as compared to those who were not employed. Results were interpreted in terms of Indian sociocultural milieu.

Keywords: Mental Health, M.M.H.S.I. t-Test Socio-cultural milieu, technical personnel.

\section{INTRODUCTION}

Psychologists since the last two decades vigorously studied mental health because of its indisputable importance for the proper adjustment of human being in various changeable situation (Ross et al. 1990; Bonne Joy \& Coroli, 1994). Helliwell \& Putnam (2004) found that impact of the employment on mental health is varied between young adults and those who were above 30 years. The cross sectional studies suggested that employment protect and foster good mental and physical health than unemployment (Kessler \& Turner, 1987; Moser et al., 1986; Main 2002; Ferrie et al., 2002; Murphy et al., 2010).

Review of literature showed that employment increase power, status recognition social support as well other economic rewards. Most of these studies were conducted in industrially developed countries where socio-cultural and economic conditions are totally different from Indian sociocultural scenario. Thus, deaths of studies in Indian context especially on young technical personnel impress us to select this problem. The present work focused on comparative study on mental health among employed and unemployed young technical (Both male/female). To achieve these above stated objectives following two hypotheses were formulated.

1. There were significant differences between mental health of employed and unemployed young technical personnel.

2. Male and female were significantly differ in their mental health status.

*Reader, Department of Psychology, Meerut College, Meerut

**Post Doctoral Fellow Department of Psychology, Meerut College, Meerut

(C) 2014 M Khokhar, V Nagar; licensee IJIP. This is an Open Access Research distributed under the terms of the Creative Commons Attribution License (http://creativecommons.org/licenses/by/2.0), which permits unrestricted use, distribution, and reproduction in any Medium, provided the original work is properly cited. 


\section{METHODOLOGY}

\section{Research Site and Sample}

The present investigation was conducted in an industrial complex of B.H.E.L. (Haridwar) and I.D.P.L (Rishikesh). Both were government undertaking Units. A sample of 100 young technical personnel was selected randomly and those consists of both male and female (employed \& unemployed). Unemployed sample was selected on the basis of assumption of those who had not permanent employment (Part time work) in the work unit.

\section{Tools Used}

Mithila Mental Health Status Inventory (MMHS) developed by Kumar and Thakur (1984) was used for measuring the mental health of technical personnel. The scale consist of 50 items. Higher scores in the inventory refers to the poor mental health. Its reliability was .90 by split half method and validity was statistically significant by comparison method.

\section{RESULTS AND DISCUSSION}

t-test was used to analysed the data. The findings obtained by t-test was given in following tables.

Table-1

Mental Health between Employed and Unemployed Young Technical Personnel

\begin{tabular}{|l|c|c|c|c|}
\hline \multicolumn{1}{|c|}{ Group Compared } & N & Mean & S.D. & t-Value \\
\hline Employed Young Personnel & 50 & 123 & 10.1 & \multirow{2}{*}{$3.22 * *$} \\
\cline { 1 - 3 } Unemployed Young Personnel & 50 & 130 & 11.1 & \\
\hline
\end{tabular}

** Significant at .01 level of significance

Table-2

Mental Health between Employed and Unemployed Male \& Female young personnel

\begin{tabular}{|l|c|c|c|c|}
\hline \multicolumn{1}{|c|}{ Grouped Compared } & N & Mean & S.D. & t-Value \\
\hline Employed Young Male personnel & 25 & 125 & 10.9 & \multirow{2}{*}{1.39} \\
\cline { 1 - 4 } Employed Young Female Personnel & 25 & 121 & 9.23 & \\
\hline Unemployed Young Male Personnel & 25 & 132 & 12.2 & \multirow{2}{*}{1.25} \\
\hline Unemployed Young Female Personnel & 25 & 128 & 102 & \\
\hline
\end{tabular}

\section{INTERPRETATION \& DISCUSSION}

Table 1 depicted that $\mathrm{t}$-value is significant at .01 level of significance. It is found that employed young technical personnel's have better mental health as compared to unemployed personnel. 
While such no difference was existed between mental health of male and female technical personnel. But mean and SD values are showing that unemployed male have poor mental health as compared to unemployed female counter parts. Findings of the present work can be interpreted in forms of different aspects of mental health status. Better mental health among technical personnel (Both male/female) depend upon the nature of their employment (especially among technical personnel) which provide them feeling of security, status, autonomy and other socio-psychological aspects of work life. Murphy et al., (2010) found that employment is an important aspect for satisfying not only biologically and security needs but also various higher order needs.

On the other hand, unemployment is a major source of stress, helplessness, frustration, economic hardship and sometimes some serious problems such as burn out and depression, damage the individuals sense of self worth that perceived themselves as shameful by others. Thus, stress, insecurity, feeling of inferiority, anxiety etc. appears to be more intense consequence of unemployment which consequently affect the mental health status of young technical personnel. Dooley et al. (2000) explained that poor quality jobs are more likely to be associated with mental health problems than better quality of jobs. When male and female young technical personnel were compared on mental health status. It was found that female have better mental health as compared to their male counterparts some cross sectional studies (Bired, Fremont 1991; Bired and Ross 1993; OECD 2008; Breslin et al. 2008) also support out above stated findings. Thus, paper has applied applications for young technical personnel. Further, studies should be conduct on a large sample with varied variable to gain its practical application Indian scenario.

\section{REFERENCE}

1. Breslin F.C, Gnam, W.; Franche, R.L.; Mustard, C.; Lin, E.(2006). Depression and activity limitations; examining gender differences in the general population. Social Psychiatry and Psychiatric Epidemiology, 41(8): 648-55.

2. Breslin, F.C.; Mustard, C. (2003). Factors influencing the impact of unemployment on mental health among young and older adults in a longitudinal, population based survey. Scandinavian Journal of Work, Environment and Health, 29(1) : 5-14.

3. Dooley, D'.; Prause, J.; Ham-Rowbottom K.A. (2003). Under employment and depression: Longitudinal Relationships. Journal of Health and Social Behaviour. 41(4) : 421-36.

4. Helliwell, J.F.; Putnam, R.D. (2004). The Social Context of Well-being. Philosophical Transactions of the Royal Society B. 359 : 1435-1446.

5. Organisation for Economic Co-operation and Development (2008). Are all jobs good for your health? The impact of work status and working conditions on mental health. OECD Employment Outlook.

6. W.H.O.(1951). Mental Health and Mental Illness in the World of Today Feature Series.

7. Gregory, C. Murphy; James, A.; (2010). Employment and Mental Health. The British 
Psychological Society. Artical First Published online 16 Dec.

8. Douglas, E. (2006). Unemployment and Mental Health : A Critical Review Department of Sociology. La Trobe University, Bundoora, Australia 3083.

9. Bired, Chlol, E.; Fremont, Allen, M. (1991). Gender, Time Use and Health" Journal of Health and Social Behavior 32 : 114-29.

10. Bired, Chlol, E \& Ross, Catherne E. (1993). House Workers and Paid Workers: Qualities of the work and Effects on Personal Control. Journal of Marriage and The Family, 55913-25.

11. Conger, Rand D.; Elder, Glen, H. (1994). Families in Troubled Times New York Aldine Grwfter.

12. Kessler, Ronald, C \& House James S. Turner J. Black (1987). Unemployment and Health in a Community Sample" Journal of Health and Social Behaviour 28-51-59.

13. Kumar, Thakur (1984). Unemployment and Health in a Community Sample, Journal of Health and Social Behaviour.

14. Moser, K.A.; Fox, A.J. \& Jones, D.R. (1986). Unemployment and Mortality in the OPXS Longitudinal Study pp 75-78 in class and Health Research in Longidutional Data Edited by R.G. Wilkness London England.

15. Ross, Catherine, E; Mirowsky, J; Gold, Stein, K. (1990). The Impact of the Family on Health. The Decade in Review. Journal of Marriage and the Family, 52-1059-78. 